\title{
Percepção da administração tópica ocular de drogas: aplicador facial x gotas
}

\author{
Topical drug administration perception with and \\ without eye drop applicator
}

Arlindo José Freire Portes ${ }^{1}$, Marina Gabriela de Oliveira e Silva², Marcella Viana ${ }^{3}$, Angela Flores Paredes ${ }^{4}$, Julia Rocha ${ }^{5}$

\section{RESUMO}

Objetivos: Avaliar por meio de questionário, qual o grau de dificuldade para aplicação tópica de medicações oculares, com ou sem o auxílio do apoio facial. Observar qual método foi tecnicamente melhor utilizado para aplicação de drogas tópicas oculares. Métodos: O estudo foi um ensaio clínico controlado e randomizado, realizado em 50 pacientes no decorrer de 2009 e 2010 na Unidade de Saúde da Família - Lapa. Foi utilizado um frasco de colírio Oftane ${ }^{\circledR}$ e o mesmo foi acoplado ao dispositivo de apoio facial. Cada participante aplicou em cada um dos olhos, a solução com ou sem o uso do dispositivo, sendo que a seleção foi feita através de um processo randomizado. Foi perguntado ao paciente questões pré-formuladas sobre a praticidade de ambos os métodos. Resultados: Considerando o grau de dificuldade de administração tópica ocular: $12 \%$ acharam difícil ou muito difícil a aplicação com o objeto de apoio facial e $22 \%$ sem o apoio $(\mathrm{p}=0,0024)$. As dificuldades descritas pelos pacientes foram relatadas por $22 \%$ dos pacientes para aplicação com o dispositivo de apoio facial e por $46 \%$ para aplicação sem o mesmo. Já 34\% dos pacientes necessitaram de mais de uma instilação para aplicação do colírio sem o apoio, enquanto que 54\% dos pacientes precisaram de mais de uma aplicação para que a gota atingisse o olho com o auxílio do apoio facial $(\mathrm{p}=0,04)$. Em $56 \%$ dos pacientes houve toque da ponta do colírio com os tecidos oculares, quando o objeto de apoio facial não foi usado, porém quando ele foi utilizado, apenas $2 \%$ dos pacientes observados tocaram os tecidos oculares ( $\mathrm{p}=0,0001)$. Conclusão: É mais fácil a instilação de colírios com o auxílio do dispositivo de apoio facial. Este também dificulta o contato da ponta do frasco com os tecidos oculares, prevenindo a contaminação do frasco.

Descritores: Administração tópica; Soluções oftálmicas/administração \& dosagem; Lubrificantes; Olho/efeitos de drogas

\footnotetext{
1Professor Adjunto de Oftalmologia da Universidade Estácio de Sá Rio de Janeiro (RJ), Brasil;

${ }^{2}$ Acadêmica do $6^{\circ}$ ano do Curso de Medicina da Universidade Estácio de Sá Rio de Janeiro (RJ), Brasil; ${ }^{3}$ Acadêmica do $6^{\circ}$ ano do Curso de Medicina da Universidade Estácio de Sá Rio de Janeiro (RJ), Brasil;

${ }^{4}$ Acadêmica do $6^{\circ}$ ano do Curso de Medicina da Universidade Estácio de Sá Rio de Janeiro (RJ), Brasil;

${ }^{5}$ Acadêmica do $6^{\circ}$ ano do Curso de Medicina da Universidade Estácio de Sá Rio de Janeiro (RJ), Brasil.
}

Os autores declaram inexistir conflitos de interesse.

Recebido para publicação em: 28/7/2010 - Aceito para publicação em 22/4/2011 


\begin{abstract}
Objective:Evaluate how difficult it is to apply ocular topical medications with and without an eye dropper facial applicator based on patient observation and answers to a questionnaire. Methods: The study was a controlled and randomized clinical trial performed in 50 patients during the years of 2009 and 2010 in PSF - Lapa. Eye drops were applied with and without aid of an eye dropper facial applicator. Each individual tested applied randomly on one of their eyes an eye drop with or without the applicator. The patients had to answer questions about the practice concerning both forms of topical eye drug application. Results: $12 \%$ informed that it was difficult or very difficult to instill eye drops and $22 \%$ to instill eye drops helped by an eye dropper facial applicator (0,0024). Problems described by patients were considered by $22 \%$ for eye drops with the applicator and by $46 \%$ for topical eye drop instillation without it. $34 \%$ of the patients needed more than one eye drop application to have eye drop contact, while $54 \%$ of the patients needed more than one application with the eye drop facial applicator in order to get drug eye contact $(p=0,04)$. In $56 \%$ of patients there were an eyedropper tip contact with ocular tissues, however there was only $2 \%$ of contact when the eye drop was instilled aided by the applicator ( $p=0,0001)$. Conclusion: It is easier to instill an eye drop with the help of an eye dropper applicator than without it. This dispositive also reduces the eyedropper tip contact with the ocular tissues.

Keywords:Administration, topical; Ophthalmic solutions/administration \& dosage; Lubricants; Eye/drug effects
\end{abstract}

\section{INTRODUÇÃO}

A o contrário dos tratamentos médicos baseados na ingestão de medicamentos por via oral, o uso correto de colírios depende de uma técnica de administração baseada em movimentos de coordenação motora fina ${ }^{(1)}$. Muitos pacientes, notadamente os idosos ou aqueles portadores de doenças que afetam esta coordenação, como por exemplo: tremor essencial ou síndrome de Parkinson têm dificuldade em aplicar medicações tópicas oculares.

A boa acuidade visual para perto é requisito necessário para a aplicação adequada de colírio, pois há necessidade de se observar a aproximação da ponta do frasco e mantê-la próxima do olho em posição adequada antes de apertar o dispositivo. Muitos pacientes com deficiência visual para perto, como por exemplo, os présbitas, portadores de catarata, pacientes com altas ametropias, idosos, indivíduos em pós-operatórios ou vítimas de traumas oculares, poderão ter dificuldade de executar esta manobra.

Vários estudos demonstraram que o uso incorreto de colírios pode acarretar o aumento da absorção sistêmica das drogas, com consequente maior toxicidade ${ }^{(2)}$.

O uso incorreto ocorre quando se usa número excessivo de gotas por aplicação ou número excessivo de aplicações das gotas ${ }^{(3)}$.

Ardência, lacrimejamento e queimação são sensações desagradáveis comumente experimentadas pelos pacientes que usam colírios. Devido a sua pouca cooperação, as crianças são um grupo em que o uso de gotas representa um transtorno para o profissional de saúde realizar um tratamento, uma vez que este grupo apresenta maior dificuldade em manter os olhos abertos para

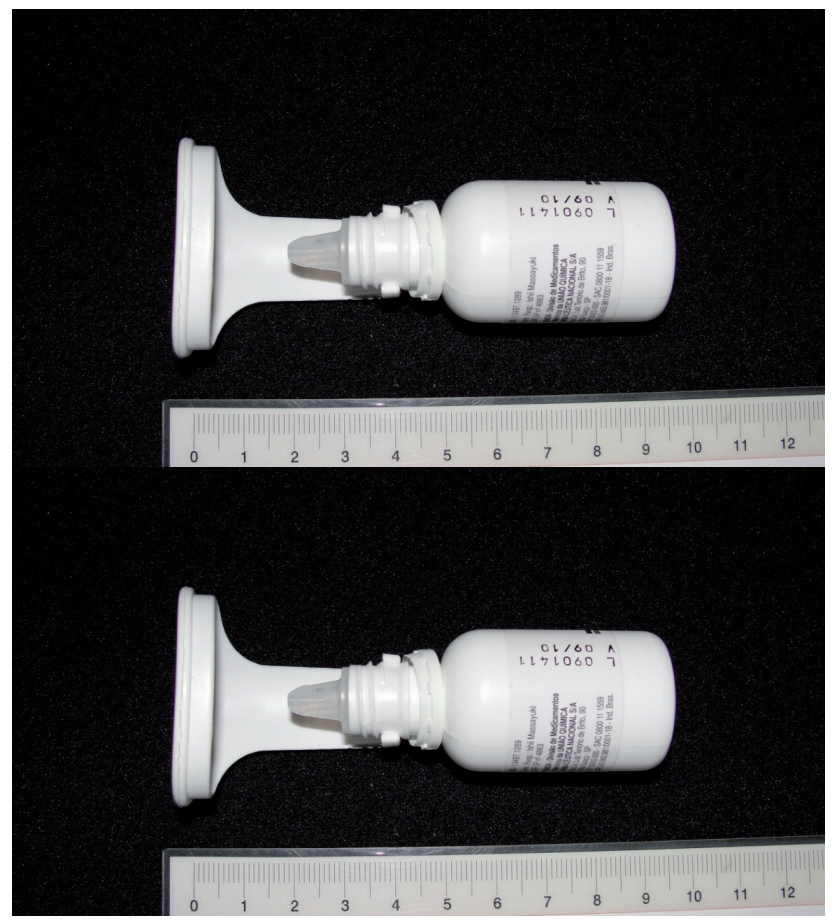

Figura 1: Dispositivo de apoio facial

o colírio ser aplicado. Em 2006, Tavares e Portes demonstraram que o efeito midriático da gota de tropicamida a $1 \%$ era equivalente ao da vaporização do mesmo medicamento em olhos de crianças ${ }^{(4)}$.

Alguns dos mais importantes fatores que levam os pacientes a não aderirem adequadamente ao tratamento com colírios podem estar relacionados à instilação incorreta destes, o que eleva o custo da terapêutica ${ }^{(3)}$.

A instilação do medicamento ocular quando o frasco do colírio é acoplado a um dispositivo de apoio facial (Figura 1) pode facilitar o tratamento naqueles com dificuldades de manter boa coordenação motora. 


\section{Anexo 1 - Questionário utilizado.}

1. Número do Prontuário:

2. Iniciais do Paciente:

3. Idade:

4. Em relação à instilação de colírio, você considera:
1) Muito fácil (
) 2) Fácil ( ) 3) Nem fácil nem difícil (
4) Difícil
) 5) Muito Difícil ( )

5. Em relação à administração com auxílio do aplicador facial, você considera:
1) Muito fácil (
2) Fácil (
3) Nem fácil nem difícil (
) 4) Difícil (
5) Muito Difícil ( )

6. Em relação à instilação de colírio, você possui alguma dificuldade?

( ) Sim ( ) Não

Qual?

7. Em relação a administração tópica com aplicador facial, você possui alguma dificuldade?

( ) Sim ( ) Não

Qual?

Observação:

Em relação ao colírio:

8. A gota instilada caiu no olho? ( ) Sim ( ) Não

9. Houve necessidade de repetição da instilação para ela cair nos olhos?

( ) $\operatorname{Sim}$ ( ) Não

10. A ponta do colírio tocou os cílios? ( ) Sim （ ) Não

11. Quantas gotas foram aplicadas?

Em relação ao dispositivo de apoio:

12. A gota do frasco atingiu o olho? ( ) Sim （ ) Não

13. Houve necessidade de repetição? ( ) Sim ( ) Não

14. Houve toque da ponta do frasco com os tecidos oculares?

( ) Sim ( ) Não

15. Quantas vaporizações foram realizadas?

Trabalhos publicados na literatura demonstraram que muitos pacientes aplicam erroneamente as gotas instiladas nos olhos ao tocar a ponta do colírio nos tecidos oculares ${ }^{(2,5)}$.Para auxiliar na instilação de colírios vários dispositivos foram idealizados e estão presentes no mercado de outros países, como por exemplo: "Eyeot", "E-Z Drops", "Eye Drop Administrator", etc ${ }^{(6,7)}$.

Após extensa pesquisa em bases de dados eletrônicas (Medline, Scielo, Lilacs), não encontramos dispositivos para auxílio de aplicação tópica de colírios a venda no Brasil, porém eles existem em vários outros países.

Os objetivos deste trabalho foram: avaliar de acor- do com questionário qual o nível de facilidade ou dificuldade para aplicação tópica de medicações oculares: gotas x aplicação com auxílio de apoio facial; avaliar de acordo com a observação do paciente qual o método que foi utilizado com maior adequação técnica na aplicação de drogas tópicas oculares.

\section{MÉTODOS}

O estudo foi um ensaio clínico controlado e randomizado, realizado em 50 pacientes no período de setembro de 2009 a fevereiro de 2010 no Programa Saú- 
de da Família (PSF) Lapa.

Foi utilizado um frasco de colírio de solução de lubrificante ocular (Oftane ${ }^{\circledR}$ ) acoplada a um apoio facial e o mesmo colírio sem o apoio.

Os pacientes foram avaliados em sala de consultório médico em que estava presente uma cadeira e uma maca, de forma que os pacientes pudessem realizar a instilação, tanto quanto possível, da mesma maneira que estavam habituados a fazê-la em seu próprio ambiente.

Foi fornecido para cada participante um frasco de colírio de solução lubrificante ocular (Oftane®), e foi solicitado que efetuasse a instilação do mesmo em um dos olhos previamente selecionado através de um processo randomizado por uma tabela pseudoaleatória do Excel.

Só foram incluídos pacientes que disseram saber instilar colírios nos olhos.

No outro olho foi solicitado que o participante aplicasse a solução de Oftane ${ }^{\circledR}$ com auxílio do aplicador facial.

Todo o processo foi acompanhado pelos autores.

Após o processo, foi perguntado ao paciente questões pré-formuladas sobre a praticidade de ambos os métodos (Anexo 1).

Após a coleta dos dados, os mesmos foram avaliados estatisticamente no programa Biostat 5.0. Foi utilizado o teste de "Mann - Whitney" para as respostas das perguntas 4 e 5 do questionário (Anexo 1); o teste binomial: duas proporções para as respostas das perguntas $8,9,10,12,13,14$ e o teste t: duas amostras para as respostas das perguntas 11 e 15 .

Aspectos éticos: Esta pesquisa foi submetida e aprovada pelo Comitê de Ética em Pesquisa da Universidade Estácio de Sá.

\section{Resultados}

A média de idade dos pacientes foi de 52,84 anos. Setenta e seis por cento (76\%) eram do sexo feminino.

Dos 50 pacientes estudados em relação à instilação de colírios: $44 \%$ acharam fácil ou muito fácil a instilação de colírio sem o apoio facial, enquanto que $70 \%$ acharam muito fácil ou fácil a instilação com o apoio. Por outro lado, $22 \%$ acharam difícil ou muito difícil à aplicação do colírio e $12 \%$ acharam difícil ou muito difícil o uso do apoio facial (tabela 1).

Quando perguntados se havia dificuldade em relação à aplicação do colírio: $48 \%$ dos entrevistados disseram que sim, sendo que a maior dificuldade foi de direcionar a gota no olho (32\%), seguida do desconheci-
Tabela 1

Grau de dificuldade de instilação de colírio

\begin{tabular}{ccc}
\hline $\begin{array}{c}\text { Grau de } \\
\text { dificuldade }\end{array}$ & $\begin{array}{c}\text { Colírio } \\
(\%)\end{array}$ & $\begin{array}{c}\text { Aplicador } \\
\text { facial (\%) }\end{array}$ \\
\hline 1 & 2 & 28 \\
2 & 42 & 42 \\
3 & 34 & 16 \\
4 & 22 & 12 \\
5 & 0 & 1 \\
Total & $\mathbf{1 0 0}$ & $\mathbf{1 0 0}$ \\
\hline
\end{tabular}

1-Muito fácil; 2-Fácil; 3-Nem fácil nem difícil; 4- Difícil; 5- Muito difícil $(\mathrm{p}=0,0024)$

Tabela 2

Tipo de dificuldade relatada pelos entrevistados

\begin{tabular}{lcc}
\hline Tipo de dificuldade & $\begin{array}{c}\text { Colírio } \\
(\%)\end{array}$ & $\begin{array}{c}\text { Aplicador facial } \\
(\%)\end{array}$ \\
\hline Direcionar a gota & 18 & 10 \\
Posição ideal & 6 & 4 \\
Aflição/medo & 4 & 2 \\
Técnica & 2 & 2 \\
Toca a ponta do frasco & & \\
nos tecidos oculares & 2 & 2 \\
$>01$ dificuldade & 16 & 2 \\
Não apresenta dificuldades & 52 & 78 \\
Total & 100 & 100 \\
\hline
\end{tabular}

Tabela 3

Necessidade de repetição da aplicação

\begin{tabular}{ccc}
\hline $\begin{array}{c}\text { Necessidade } \\
\text { de repetição }\end{array}$ & $\begin{array}{c}\text { Colírio } \\
(\mathbf{\%})\end{array}$ & $\begin{array}{c}\text { Aplicador facial } \\
(\mathbf{\%})\end{array}$ \\
\hline Sim & 34 & 54 \\
Não & 66 & 46 \\
Total & 100 & 100 \\
\hline$(\mathrm{p}=0,04)$ & &
\end{tabular}

Tabela 4

Toque da ponta do frasco em tecidos oculares observação dos autores

\begin{tabular}{ccc}
\hline Toque do frasco & $\begin{array}{c}\text { Colírio } \\
(\mathbf{\%})\end{array}$ & $\begin{array}{c}\text { Aplicador facial } \\
(\%)\end{array}$ \\
\hline Sim & 56 & 2 \\
Não & 44 & 98 \\
Total & 100 & 100 \\
\hline
\end{tabular}

$(\mathrm{p}=0,0001)$ 
mento da técnica correta (18\%).

Em relação ao dispositivo de apoio facial, 24\% dos entrevistados tiveram dificuldade, sendo que a maior delas foi direcionar a gota (10\%), (tabela 2).

Foram observados pelos autores se durante a aplicação do colírio houve a necessidade de uma nova aplicação para que a gota caísse no olho: $34 \%$ apresentaram necessidade de uma nova instilação sem o auxílio do apoio facial e $54 \%$ apresentaram necessidade de uma nova aplicação com o apoio facial $(\mathrm{p}=0,04 /$ tabela 3$)$.

Cinquenta e quatro por cento dos entrevistados encostaram a ponta do frasco nos cílios ou pálpebras ao instilar o colírio sem o aplicador facial e $2 \%$ encostaram nos tecidos oculares, quando o colírio foi aplicado com o auxílio do apoio facial ( $\mathrm{p}=0,0001$ / tabela 4).

Não houve relevância estatística dos seguintes itens: gotas que atingiram o olho $(\mathrm{p}=0,67)$ e número de gotas aplicadas $(\mathrm{p}=0,06)$, segundo a avaliação dos autores.

\section{Discussão}

Não observamos nenhum estudo comparando a percepção do paciente sobre a instilação de colírios com e sem o auxílio do aplicador facial após revisão bibliográfica extensa em bancos de dados nacionais e internacionais, como Scielo, Medline, Lilacs.

Constatamos no nosso trabalho que a maioria dos entrevistados apresentaram maior facilidade de aplicação do colírio mediante o uso do apoio facial, devido ao contato do dispositivo com a região orbitária, já que este confere maior estabilidade, minimiza os possíveis tremores, direciona melhor a gota no olho, evita o contato com os tecidos oculares e posiciona adequadamente o frasco em relação ao olho.

Vaidergon et al. ${ }^{(2)}$ observaram no seu estudo uma grande deficiência por parte da população estudada, na simples técnica de instilar um colírio, o que acarretou desperdício de parte do conteúdo do frasco e possibilidade de toxicidade devido a um maior número de gotas aplicadas. No mesmo estudo, não houve correlação estatística entre o número de gotas instiladas e o tempo de tratamento. Portanto é fundamental o ensino da técnica adequada da aplicação do colírio, mesmo para aqueles pacientes que o utilizam há muitos anos, independente da sua escolaridade e do nível socioeconômico.

A utilização da técnica correta é de suma importância, pois a sua realização inadequada pode implicar em um maior número de gotas aplicadas, o que leva a um maior custo e, consequentemente, a pior adesão ao tratamento ${ }^{(2)}$.

Apesar de os entrevistados terem referido dificuldades tanto na aplicação do colírio quanto com o auxílio do dispositivo em relação a direcionar a gota e encontrar o posicionamento ideal, a aplicação sem o dispositivo mostrou-se mais difícil do que com ele (tabela 2).

Percebemos no presente estudo que houve uma maior necessidade de mais de uma aplicação do colírio com o dispositivo. Este fato deve-se talvez a falta de hábito e desconhecimento da utilização do produto, assim como foi relatado por alguns pacientes.

Observamos que o dispositivo de apoio facial é um auxílio à administração de drogas oculares menos complicado do que a vaporização, proposta por Portes et al. ${ }^{(4)}$ no ano de 2009 , uma vez que $70 \%$ das pessoas que utilizaram o dispositivo de apoio facial acharam fácil ou muito fácil em relação ao colírio,enquanto que $42 \%$ dos pacientes que usaram vaporização acharam fácil ou muito fácil quando comparadas ao uso de colírios.

De acordo com o estudo de Höfling-Lima ${ }^{(8)} \mathrm{em}$ 2001, com 127 frascos de colírio, com soro autólogo dos pacientes, foi verificado que $76,3 \%$ estavam contaminados após o término do conteúdo do frasco, devido ao toque da ponta do colírio nos tecidos oculares. Os microorganismos mais encontrados foram os da microbiota local e germes de pele.

Ao comparar o uso do colírio com e sem o apoio facial, podemos verificar que houve um baixo índice de toque da ponta do colírio quando usado com o dispositivo, o que pode significar uma menor taxa de contaminação do frasco com o uso do mesmo. Uma das possíveis justificativas para haver contaminação apesar do uso do dispositivo é provavelmente a presença de olhos proptóticos, cílios alongados e demais alterações anatômicas.

Segundo Vaidergon et al. ${ }^{(2)}$, o contato da ponta do frasco com os tecidos oculares leva a sucção do filme lacrimal, podendo alterar as propriedades farmacológicas do colírio. Por isso a importância de evitar a contaminação para prevenir não só as infecções e ulcerações, mas também a composição da substância presente no frasco.

\section{Conclusão}

O presente estudo demonstrou que o dispositivo de apoio facial é uma ferramenta útil para administração tópica de drogas oculares.As dificuldades encontradas pelos pacientes ao instilar colírios foram menores 
quando usaram o dispositivo.

O toque da ponta do frasco de colírios em estruturas oculares foi significativamente inferior quando houve instilação de gotas através do aplicador facial, o que poderia reduzir a contaminação de frascos de colírios.

\title{
REFERÊNCIAS
}

1. Dietlein TS, Jordan JF, Lüke C, Schild A, Dinslage S, Krieglstein GK. Self-application of single-use eyedrop containers in an elderly population: comparisons with standard eyedrop bottle and with younger patients. Acta Ophthalmol. 2008;86(8):856-9.

2. Vaidergorn PG, Malta RFS, Borges AS, Menezes MDR, Trindade ES, Malta JBNS. Técnica da instilação de colírios em pacientes portadores de glaucoma crônico. Arq Bras Oftalmol. 2003;66(6):865-9.

3. Stillitano IG, Lima MG, Ribeiro MP, Cabral J, Brandt CT. Impacto econômico do custo de colírios no tratamento do glaucoma. Arq Bras Oftalmol. 2005;68(1):79-84.

4. Tavares MO, Portes AJF. Efeito midriático da tropicamida a 1\%: vaporização x gota. Rev Bras Oftalmol. 2006;65(1):7-12.

5. Portes AJF, Gomes LP, Amaral BLMB, Massa L. Percepção da administração tópica ocular de drogas: vaporização x gotas. Rev Bras Oftalmol. 2009;68(6):327-31.

6. Meddirect - The buyers guide for NZ'S medical industry. Eye Drop Administrator. Available from: http:// www.meddirect.co.nz/Product.aspx?ProductId $=4925$.

7. E-Z drops - Eye drop application strips. Available from: http:/ lezdrops.com/ .

8. Höfling-Lima AL, Lima AS, Batistoso JA, Kawamura D, Chalita MRC, Alves LS, Farah ME. Contaminação de frascos de colírios de soro autólogo. Arq Bras Oftalmol. 2001;64(1):63-5.

\author{
Endereço para correspondência: \\ Arlindo Portes \\ Rua Riachuelo, $n^{\circ} 43$ - Lapa \\ CEP 20230-010 - Rio de Janeiro (RJ), Brasil \\ e-mail:portes@uol.com.br
}

